Article

\title{
Bio-Guided Isolation of Prospective Bioactive Constituents from Roots of Clausena indica (Dalzell) Oliv
}

\author{
Nguyen Van Quan ${ }^{1}\left(\mathbb{D}\right.$, Tran Dang Xuan ${ }^{1, *} \mathbb{D}$, La Hoang Anh ${ }^{1}$ and Hoang-Dung Tran ${ }^{2}(\mathbb{D}$ \\ 1 Department of Development Technology, Graduate School for International Development and Cooperation, \\ Hiroshima University, Hiroshima 739-8529, Japan; nguyenquan26@gmail.com (N.V.Q.); \\ hoanganh6920@gmail.com (L.H.A.) \\ 2 Faculty of Biotechnology, Nguyen Tat Thanh University, 298A-300A Nguyen Tat Thanh Street, Ward 13, \\ District 4, Ho Chi Minh City 72820, Vietnam; thdung@ntt.edu.vn \\ * Correspondence: tdxuan@hiroshima-u.ac.jp; Tel./Fax: +81-82-424-6927
}

Academic Editor: Alessandra Guerrini

Received: 30 October 2019; Accepted: 2 December 2019; Published: 4 December 2019

check for updates

\begin{abstract}
Clausena indica fruits are routinely used for the culinary purpose as natural spices, whereas leaves and roots are folk medicine with various health benefits in southern China, South and Southeast Asia. In this study, the bioassay-guided fractionation by column chromatography yielded three pure compounds including dentatin, nordentatin, and clausine $\mathrm{K}$ and five active fractions (Re1-5) from C. indica roots. These known anticancer compounds were confirmed by $\mathrm{X}$-ray diffraction, ${ }^{1} \mathrm{H}$-, ${ }^{13} \mathrm{C}$-nuclear magnetic resonance (NMR), and electrospray ionization tandem mass spectrometric (ESI-MS-MS) analyses. Meanwhile, the phytochemical constituents from fractions were identified by gas chromatography-mass spectrometry (GC-MS). The isolates, fractions' components and their biological activities were first time investigated on C. indica. By in vitro DPPH and ABTS scavenging assays, nordentatin $\left(\mathrm{IC}_{50}=49.2\right.$ and $69.9 \mu \mathrm{g} / \mathrm{mL}$, respectively) and the fraction $\operatorname{Re} 4(32.4$ and $38.5 \mu \mathrm{g} / \mathrm{mL}$, respectively) showed the strongest antiradical activities, whereas clausine $\mathrm{K}$ presented a moderate and dentatin had negligible antioxidant activity, respectively. The anti- $\alpha$-amylase activity of $C$. indica root extracts was mainly attributed to the fraction $\mathrm{Re} 2$ which inactivated the enzymatic assay with $\mathrm{IC}_{50}$ of $573.8 \mu \mathrm{g} / \mathrm{mL}$. Among tested samples, only nordentatin and clausine K were effective in the pancreatic elastase inhibition, however, their influences were trivial. Markedly, clausine $\mathrm{K}$ and Re4 performed the most remarkable tyrosinase inhibition with $\mathrm{IC}_{50}$ values of 179.5 and $243.8 \mu \mathrm{g} / \mathrm{mL}$, respectively, which were in turn 4 and 3 times stronger than myricetin $\left(\mathrm{IC}_{50}=735.6 \mu \mathrm{g} / \mathrm{mL}\right.$ ), a well-known tyrosinase inhibitor. This is the first report affirming clausine $\mathrm{K}$ to be a new strong tyrosinase inhibitor. Isolated compounds from $C$. indica roots were quantified by high-performance liquid chromatography (HPLC), of which, dentatin, nordentatin, and clausine K accounted for 14.74, 6.14, and $1.28 \mathrm{mg} / \mathrm{g}$ dry weight. The findings suggest that bioactive constituents from $C$. indica roots may be potentially employed for the development of antidiabetic, antiaging and cosmetic agents.
\end{abstract}

Keywords: Clausena indica; dentatin; nordentatin; clausine K; antioxidants; anti- $\alpha$-amylase; anti-elastase; anti-tyrosinase

\section{Introduction}

Clausena indica (Dalzell) Oliv. is an evergreen small tree that belongs to the citrus family, Rutaceae. The plant is widely distributed in South China and South and Southeast Asia [1]. The C. indica species is traditionally used for multiple purposes as foodstuffs and folk medicines. In Vietnam, leaves and fruits of C. indica are mainly used for cooking as natural spices, which can increase the food's flavor 
and attractivity. Besides, its leaves and roots are customarily utilized in curing a cold, flu, headache, colic, and rheumatism. The leaf essential oil possesses antimicrobial and antibacterial activities [1,2]. Numerous phytochemical components were earlier reported in C. indica roots by Joshi and coworkers, of which coumarins, carbazole alkaloid (6-methoxyheptaphylline), and sesquiterpenes were the lead compounds [3-6]. On the other hand, plants in the Clausena genus were scientifically documented as a diverse source of anticancer agents, in which coumarins and carbazole alkaloids are the most dominant anti-carcinogenic compounds isolated from this genus [7]. While carbazole alkaloids have been found from various Clausena species, coumarins have been detected mostly in C. harmandiana and C. excavata [7]. However, the compounds from C. indica roots and their involvement in the biological activities of this species have not been investigated adequately.

In humans, reactive oxygen species (ROS) are invariably produced in the body via redox reaction [8]. ROS are well known as potential products having harmful effects on the essential constituents of living cells [9] which may result in a serious development of oxidative stress and many human diseases such as skin pigmentation, type 2-diabetes, and cancers [10]. Recently, a strong association among skin manifestations, diabetes and obesity were reported with trustworthy documentation in both clinical and practical trials [11,12]. Therefore, studies on antioxidants can be regarded as the prerequisite for various related anti-disease effects such as diabetes and skin diseases. In the context of the current drug development, antioxidants that have natural provenance are the most selective priority owing to their advantageous safety and availability [13]. Some outstanding sources such as phenolics, flavonoids, and secondary metabolites, especially derived from plants, are being widely exploited in the pharmaceutical industry [14]. The phytochemicals with health benefits are expected to be considered as a substitute for synthetic drugs that may cause various side-effects. Hence, the discovery of natural metabolites exhibiting a remarkable resistance to a wide range of dangerous diseases can be a potential approach in phytochemicals and pharmacological studies.

The above-mentioned rationales prompted us to conduct this study aiming to isolate bioactive compounds from the extract of Clausena indica roots and to examine their contributions to antioxidant, antidiabetic, and anti-skin-aging properties. This study proposes effective analytical methods to isolate and purify bioactive constituents from $C$. indica and give insights to future research targeting to novel drugs that can control multiple diseases.

\section{Results and Discussion}

\subsection{Isolation, Identification, and Confirmation of Bioactive Compounds from Clausena Indica Roots}

The ethyl acetate extract (MRE, $7 \mathrm{~g}$ ) separated from total methanolic extract (MRT) accounted for $4.6 \%$ of the dry weight of the sample. By a normal phase column chromatography, MRE was fractionated into five fractions $\operatorname{Re} 1-\operatorname{Re} 5$ which were $1.4 \%, 0.4 \%, 0.7 \%, 0.1 \%$, and $0.3 \%$ of the extraction efficiency, respectively. Meanwhile, the yields of isolated compounds dentatin (L1), nordentatin (L2), and clausine $\mathrm{K}(\mathrm{L} 3)$ were $0.5 \%, 0.4 \%$, and $0.1 \%$, respectively. The three compounds were isolated from C. indica roots for the first time (Figure 1). 
<smiles>[R]Oc1c2c(c(C(C)(C)C=C)c3oc(=O)c([2H])cc13)OC(C)(C)C([R])=C2</smiles>

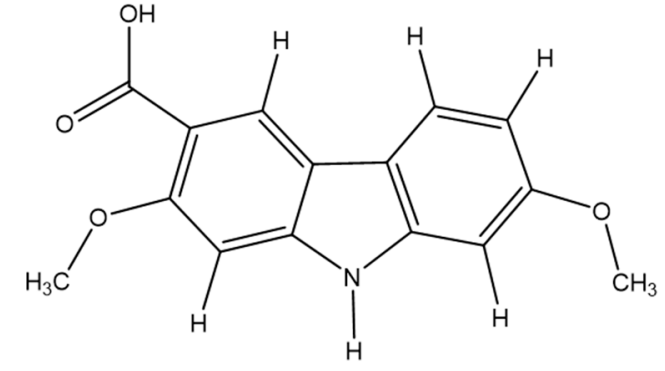

Clausine $\mathrm{K}(\mathbf{L} 3)$

Figure 1. Chemical structures of isolated compounds from Clausena indica roots.

Chemical structures of purified metabolites refined by $\mathrm{X}$-rays diffraction (Table 1 ), $1 \mathrm{D}-{ }^{1} \mathrm{H}$ - and ${ }^{13} \mathrm{C}$-nuclear magnetic resonance (NMR) and electrospray ionization mass spectrometry (ESI-MS) were identical compared with those in literature [15,16] (Supplementary data, Tables S1-S3, Figures S1-S3).

Table 1. Crystal data for dentatin, nordentatin and clausine K.

\begin{tabular}{|c|c|c|c|}
\hline & Dentatin & Nordentatin & Clausine $\mathrm{K}$ \\
\hline Chemical formula & $\mathrm{C}_{20} \mathrm{H}_{22} \mathrm{O}_{4}$ & $\mathrm{C}_{19} \mathrm{H}_{20} \mathrm{O}_{4}$ & $\mathrm{C}_{15} \mathrm{H}_{13} \mathrm{NO}_{4}$ \\
\hline Molecular weight & $326.39 \mathrm{~g} / \mathrm{mol}$ & $313.36 \mathrm{~g} / \mathrm{mol}$ & $271.26 \mathrm{~g} / \mathrm{mol}$ \\
\hline Temperature & $173(2) \mathrm{K}$ & $173(2) \mathrm{K}$ & $173(2) \mathrm{K}$ \\
\hline Wavelength & $0.71073 \AA$ & $0.71073 \AA$ & $0.71073 \AA$ \\
\hline Crystal size & $0.020 \times 0.170 \times 0.200 \mathrm{~mm}$ & $0.080 \times 0.130 \times 0.250 \mathrm{~mm}$ & $0.090 \times 0.090 \times 0.130 \mathrm{~mm}$ \\
\hline Crystal habit & clear pale-yellow plate & clear light-yellow block & clear yellow block \\
\hline Crystal system & triclinic & monoclinic & monoclinic \\
\hline Space group & P -1 & P 1 21/n 1 & P 1 21/n 1 \\
\hline & $\mathrm{a}=9.330(8) \AA \quad \alpha=102.188(9)^{\circ}$ & $\mathrm{a}=11.685(10) \AA$ & $\mathrm{a}=7.032(4) \AA$ \\
\hline Unit cell dimensions & $\begin{array}{ll}\mathrm{b}=9.472(8) \AA & \beta=105.805(9)^{\circ} \\
\mathrm{c}=10.380(9) \AA & \gamma=90.679(9)^{\circ}\end{array}$ & $\begin{array}{cc}\mathrm{b}=10.832(9) \AA & \beta=94.009(9)^{\circ} \\
\mathrm{c}=12.596(10) \AA & \gamma=90^{\circ}\end{array}$ & $\begin{array}{lc}\mathrm{b}=14.522(9) \AA & \beta=99.276(7)^{\circ} \\
\mathrm{c}=12.660(8) \AA & \gamma=90^{\circ}\end{array}$ \\
\hline Volume & $860.4(12) \AA^{3}$ & 1590.(2) $\AA^{3}$ & $1275.9(13) \AA^{3}$ \\
\hline $\mathrm{Z}$ & 2 & 4 & 4 \\
\hline Density (calculated) & $1.260 \mathrm{~g} / \mathrm{cm}^{3}$ & $1.309 \mathrm{~g} / \mathrm{cm}^{3}$ & $1.412 \mathrm{~g} / \mathrm{cm}^{3}$ \\
\hline $\begin{array}{l}\text { Absorption } \\
\text { coefficient }\end{array}$ & $0.087 \mathrm{~mm}^{-1}$ & $0.091 \mathrm{~mm}^{-1}$ & $0.104 \mathrm{~mm}^{-1}$ \\
\hline $\mathrm{F}(000)$ & 348 & 668 & 568 \\
\hline
\end{tabular}

Along with three purified metabolites, phytochemical contents of $C$. indica roots were preliminarily identified by gas chromatography-mass spectrometry (GC-MS). The results are delineated in Table 2. Among 18 compounds detected from two extracts (MRT and MRE) and five fractions (Re1-Re5), 10 compounds were certainly confirmed including palmitic acid [17], seselin [18], L-5-propylthiomethylhydantoin [19], braylin [20], anisocoumarin B [21], dentatin [16], nordentatin [16], clausine K [16], 7-hydroxyheptaphylline [16], clionasterol [22]. On the other hand, three unknown compounds 1 (UC1), 2 (UC2) and 3 (UC3) were found at retention times 20.24, 20.85 and $21.08 \mathrm{~min}$, respectively. Of which, UC1 was the most abundant compound in $\operatorname{Re} 3(58.7 \%)$ and $\operatorname{Re} 4(26.1 \%)$ while UC3 was only observed in Re3 (2.8\%). UC2 was $2.1 \%$ and $2.3 \%$ in $\operatorname{Re} 3$ and Re5, respectively. The mass spectra of UC1-3 by GC-MS are supplied in Supplementary data, Figure S4. Additionally, five compounds were tentatively identified as carbazole alkaloids (CA1-5) by comparing their ion-fragment composition and molecular weight with those in literature data. Accordingly, CA1 (RT $21.85 \mathrm{~min}$, $227 \mathrm{~g} / \mathrm{mol}$ ) might be either clausine $\mathrm{O}, \mathrm{V}$ [15,23] or clauszoline $\mathrm{N}$ [24]. CA3 (RT 23.34, $241 \mathrm{~g} / \mathrm{mol}$ ) was probably clausines E, I, M, P [25,26] or 1-hydroxy-7-methoxy-9H-carbazole-3-carbaldehyde [27]. CA4 (RT 24.85, $279 \mathrm{~g} / \mathrm{mol}$ ) could be clauraila B [15], or heptaphylline [23], or clausine D [28]. Meanwhile, CA2 (RT 23.29, $293 \mathrm{~g} / \mathrm{mol}$ ) and CA5 (RT 24.92, $285 \mathrm{~g} / \mathrm{mol}$ ) might be clauraila D [15] and clausine H [26], respectively. Theoretically, UC2 could be recognized as either suberosin or tryptamine isovalerate but its mass spectrum showed three precursor peaks at $m / z 229,201$, and 244 which 
were apparently peculiar (Figure S4). Also, the mentioned compounds were previously reported in C. excavata. Therefore, advanced spectroscopic techniques and isolating pure compounds should be further applied and carried out in order to increase the reliability of compound identifications from C. indica.

Table 2. Major phytochemical components of Clausena indica extracts analyzed by gas chromatography-mass spectrometry (GC-MS).

\begin{tabular}{|c|c|c|c|c|c|c|c|c|c|c|}
\hline \multirow{2}{*}{ No. } & \multirow{2}{*}{ Identified Compounds } & \multirow{2}{*}{$\begin{array}{c}\text { RT } \\
\text { (min) }\end{array}$} & \multirow{2}{*}{$\begin{array}{c}\text { MW } \\
\text { (g/mol) }\end{array}$} & \multicolumn{7}{|c|}{ Peak Area in Extracts (\%) } \\
\hline & & & & MRT & MRE & Re1 & $\operatorname{Re} 2$ & $\operatorname{Re} 3$ & Re4 & $\operatorname{Re} 5$ \\
\hline 1 & Palmitic acid & 17.05 & 256 & - & - & $<$ & 13.04 & - & - & - \\
\hline 2 & Seselin & 18.27 & 228 & 7.0 & 8.5 & 12.4 & 2.4 & - & - & 2.9 \\
\hline 3 & L-5-propylthiomethylhydantoin & 19.49 & 188 & 1.3 & 1.2 & - & - & - & - & 1.2 \\
\hline 4 & Braylin & 19.55 & 258 & 9.9 & 11.4 & 13.7 & 6.1 & - & - & - \\
\hline 5 & UC1 & 20.24 & 230 & $<$ & $<$ & - & - & 58.7 & 26.1 & - \\
\hline 6 & Anisocoumarin B & 20.36 & 246 & - & - & - & - & - & 14.1 & - \\
\hline 7 & UC2 & 20.85 & 244 & - & $<$ & - & $<$ & 2.1 & $<$ & 2.3 \\
\hline 8 & Nordentatin & 20.94 & 312 & 5.1 & 5.7 & - & $<$ & 10.9 & 2.1 & 2.9 \\
\hline 9 & UC3 & 21.08 & 297 & $<$ & $<$ & - & - & 2.8 & - & - \\
\hline 10 & Clausine $\mathrm{K}$ & 21.25 & 271 & - & $<$ & - & - & - & - & 15.0 \\
\hline 11 & Dentatin & 21.48 & 326 & 70.6 & 68.0 & 61.7 & 10.7 & - & - & - \\
\hline 12 & CA1 & 21.85 & 227 & - & $<$ & - & - & - & 2.8 & - \\
\hline 13 & CA2 & 23.29 & 293 & 1.9 & 2.3 & 3.5 & - & - & - & - \\
\hline 14 & CA3 & 23.34 & 241 & - & - & - & 10.0 & - & - & - \\
\hline 15 & CA4 & 24.85 & 279 & - & - & - & 1.9 & 1.1 & 11.2 & - \\
\hline 16 & CA5 & 24.92 & 285 & - & $<$ & - & - & 5.7 & - & - \\
\hline 17 & 7-Hydroxyheptaphylline & 25.80 & 295 & - & - & - & - & - & 9.2 & - \\
\hline 18 & Clionasterol & 28.41 & 414 & - & - & - & 10.2 & - & - & - \\
\hline
\end{tabular}

RT, retention time; MW, molecular weight; UC, unknown compound; CA, carbazole alkaloid; -, not detected; <, trace of peak area that was lower than $1 \%$.

The phytochemical components from the roots of $C$. indica were firstly reported by Joshi and Gawad in 1971 [3], in which, five furanocoumarins including imperatorin, phellopterin, chalepensin, and chalepin were considered as the first compounds isolated from C. indica roots. Later studies have isolated various coumarins, amides and carbazole alkaloids from this plant [3-6,29,30]. Apart from those components, terpenes and volatile constituents were investigated with potential antimicrobial and antibacterial activities in the essential oil of $C$. indica aerial parts $[1,2,31]$. In the present study, the first detection of dentatin, nordentatin, clausine $\mathrm{K}$ and other promising alkaloids may contribute to the diversity of natural products as well as the medicinal potentials of $C$. indica.

\subsection{Biological Activities of Clausena Indica}

The antioxidant capacities of $C$. indica extracts, fractions, and purified compounds were evaluated via 2,2-diphenyl-1-picrylhydrazyl (DPPH) and 2,2'-azino-bis (ABTS) radical scavenging tests and lipid peroxidation inhibitory assay ( $\beta$-carotene bleaching inhibition), see Table 3 . Noticeably, the fraction Re4 was the strongest radical scavenger, which showed $\mathrm{IC}_{50}$ values of 32.4 and $38.5 \mu \mathrm{g} / \mathrm{mL}$ at DPPH and ABTS assays, respectively. Among isolated compounds, nordentatin exhibited the highest antioxidant ability ( $\mathrm{IC}_{50}=49.2$ and $69.9 \mu \mathrm{g} / \mathrm{mL}$ for DPPH and ABTS assays, respectively) followed by clausine $\mathrm{K}$ with $\mathrm{IC}_{50}$ values of 2197.8 and $5264.0 \mu \mathrm{g} / \mathrm{mL}$, respectively. Both nordentatin and Re4 performed higher antioxidant activity than BHT $\left(\mathrm{IC}_{50}=82.8 \mu \mathrm{g} / \mathrm{mL}\right)$ in the ABTS assay. In contrast, dentatin had negligible effects in both radical scavenging assays. In terms of $\beta$-carotene bleaching inhibition assay, MRE (82.8\%) extract and Re5 (81.2\%) presented strongest lipid peroxidation inhibitions (LPI) which were in line with BHT (82.7\%). Among purified compounds, the LPI of nordentatin $(69.8 \%)$ was significantly higher than that of clausine K $(60.6 \%)$, whereas dentatin had an inconsequential activity $(37.9 \%)$. These results were coincident with previous reports [16,32], by which nordentatin was proven as a potent antioxidant whereas dentatin was a weak or inactive radical scavenger. On the contrary, studies on the antioxidant activity of clausine $\mathrm{K}$ are limited. Songsiang and coworkers reported that 
clausine $\mathrm{K}$ from $\mathrm{C}$. harmandiana was inactive in the DPPH assay and a trivial LPI by malondialdehyde assay [16]. In the present research, by using different modified in vitro models, we agree that clausine $\mathrm{K}$ from $\mathrm{C}$. indica is an antioxidant though its activity is not potent. Considerably, at a concentration of $500 \mu \mathrm{g} / \mathrm{mL}$, clausine $\mathrm{K}$ indicated $60.6 \%$ of LPI by the $\beta$-carotene bleaching assay. The obtained results implied that the DPPH assay used acetate buffer $(\mathrm{pH} 5.5)$ and $\beta$-carotene bleaching might be the proper approach to figure out the antioxidant activity of clausine $\mathrm{K}$. Also, previous study confirmed the acid buffer could contribute a stimulatory effect on DPPH radical scavenging speed [33]. However, in vivo assays should be further conducted to properly evaluate the antioxidant potential of clausine $\mathrm{K}$ and its applicability. Furthermore, the forceful antioxidant property of Re2-4 might be attributed to the synergic activity of UC1-3, anisocumarin B, nordentatin, CA1, CA3-5. Remarkably, UC2 and CA4 could be the most significant contributors because these two metabolites together with nordentatin were mostly detected in the active fractions Re2-4.

Table 3. Antioxidant activities of MR extracts, fractions, and isolated compounds.

\begin{tabular}{cccc}
\hline Sample & $\begin{array}{c}\text { DPPH Assay } \\
\mathbf{I C}_{\mathbf{5 0}}(\mu \mathrm{g} / \mathrm{mL})\end{array}$ & $\begin{array}{c}\text { ABTS Assay } \\
\text { IC }_{\mathbf{5 0}}(\mu \mathrm{g} / \mathrm{mL})\end{array}$ & $\begin{array}{c}\beta \text {-Carotene Assay } \\
\text { LPI (\%) }\end{array}$ \\
\hline MRT & $273.8 \pm 9.6^{\mathrm{e}}$ & $277.5 \pm 3.1^{\mathrm{f}}$ & $73.5 \pm 1.4^{\mathrm{bc}}$ \\
MRE & $172.4 \pm 1.2^{\mathrm{d}}$ & $156.0 \pm 1.3^{\mathrm{d}}$ & $82.8 \pm 1.1^{\mathrm{a}}$ \\
Dentatin & $n e$ & $n e$ & $37.9 \pm 0.8^{\mathrm{f}}$ \\
Nordentatin & $49.2 \pm 0.5^{\mathrm{b}}$ & $69.9 \pm 1.1^{\mathrm{b}}$ & $69.8 \pm 0.4^{\mathrm{cd}}$ \\
Clausine K & $2197.8 \pm 53.3^{\mathrm{f}}$ & $5264.0 \pm 164.0^{\mathrm{g}}$ & $60.6 \pm 1.1^{\mathrm{e}}$ \\
Re1 & $n e$ & $n e$ & $67.7 \pm 0.4^{\mathrm{d}}$ \\
$\operatorname{Re} 2$ & $283.5 \pm 7.0^{\mathrm{e}}$ & $188.5 \pm 3.6^{\mathrm{e}}$ & $73.7 \pm 0.1^{\mathrm{bc}}$ \\
$\operatorname{Re} 3$ & $88.1 \pm 3.2^{\mathrm{c}}$ & $149.4 \pm 3.2^{\mathrm{d}}$ & $76.4 \pm 0.7^{\mathrm{b}}$ \\
$\operatorname{Re} 4$ & $32.4 \pm 0.3^{\mathrm{ab}}$ & $38.5 \pm 0.8^{\mathrm{a}}$ & $76.1 \pm 0.5^{\mathrm{b}}$ \\
$\operatorname{Re} 5$ & $90.9 \pm 2.5^{\mathrm{c}}$ & $151.8 \pm 2.4^{\mathrm{d}}$ & $81.2 \pm 0.8^{\mathrm{a}}$ \\
BHT & $16.0 \pm 0.2^{\mathrm{a}}$ & $82.8 \pm 1.1^{\mathrm{c}}$ & $82.7 \pm 0.3^{\mathrm{a}}$
\end{tabular}

Data were mean \pm standard error (SE) $(n=3)$; Similar superscript letters in a same column show nonsignificant differences among samples at $p<0.05$. BHT, butylated hydroxytoluene; $n e$, negligible effect (inhibition $<10 \%$ at a maximum concentration of $10 \mathrm{mg} / \mathrm{mL}$ ).

By in vitro enzymatic assays, crude extracts, fractions, and isolated compounds of $C$. indica showed various levels of inhibitory actions on key enzymes related to diabetes ( $\alpha$-amylase) and skin aging (elastase and tyrosinase) (Table 4). Particularly, C. indica had a slight inhibitory effect towards $\alpha$-amylase reaction, in which, the inhibition was displayed by crude extracts MRT (IC $50=$ $1383.3 \mu \mathrm{g} / \mathrm{mL}), \operatorname{MRE}\left(\mathrm{IC}_{50}=1004.6 \mu \mathrm{g} / \mathrm{mL}\right)$ and the fraction $\operatorname{Re} 2\left(\mathrm{IC}_{50}=573.8 \mu \mathrm{g} / \mathrm{mL}\right)$. The results might be explained by the exclusive existence of palmitic acid, clionasterol and CA3 in the fraction Re2 (Table 2). Previous studies also demonstrated the effective anti-diabetic activity of palmitic acid [34] and clionasterol [35]. However, the tentative carbazole CA3 might play a role in the total inhibitory activity of $C$. indica root extracts.

Among tested samples, only nordentatin and clausine $\mathrm{K}$ were found to inhibit pancreatic elastase though their activity was not strong. At the maximum concentration of $10 \mathrm{mg} / \mathrm{mL}$, nordentatin and clausine K suppressed $41.9 \%$ and $21.9 \%$ of the elastase action. Markedly, fractions $\operatorname{Re} 3, \operatorname{Re} 4, \operatorname{Re} 5$, and clausine $\mathrm{K}$ flaunted considerable inhibition on tyrosinase (Table 4$)$. Clausine $\mathrm{K}\left(\mathrm{IC}_{50}=179.5 \mu \mathrm{g} / \mathrm{mL}\right)$ and $\operatorname{Re} 4\left(\mathrm{IC}_{50}=243.8 \mu \mathrm{g} / \mathrm{mL}\right)$ were the strongest tyrosinase inhibitors, which were in turn 4 and 3 times stronger than myricetin $\left(\mathrm{IC}_{50}=735.6 \mu \mathrm{g} / \mathrm{mL}\right)$, a well-known tyrosinase inhibitor. This is the first report of clausine $\mathrm{K}$ as a new promising tyrosinase inhibitor. Previous studies indicate elastase and tyrosinase are two key enzymes related to the degradation of skin's elasticity and the formation of skin's freckles due to the excessive UV exposure and ROS accumulation in the body [36,37]. Inhibitions of elastase and tyrosinase can prevent both skin wrinkles and skin browning. Therefore, the discovery of potential natural tyrosinase inhibitors from $C$. indica root extracts might be a good suggestion for the cosmetic industry. 
Table 4. $\alpha$-Amylase, elastase and tyrosinase inhibitions of Clausena indica extracts, fractions and isolated compounds.

\begin{tabular}{|c|c|c|c|}
\hline Sample & $\begin{array}{l}\alpha \text {-Amylase Inhibition } \\
\operatorname{IC}_{50}(\mu \mathrm{g} / \mathrm{mL})\end{array}$ & $\begin{array}{l}\text { Elastase Inhibition } \\
\text { at } 10 \mathrm{mg} / \mathrm{mL}(\%)\end{array}$ & $\begin{array}{l}\text { Tyrosinase Inhibition } \\
\text { IC }_{50}(\mu \mathrm{g} / \mathrm{mL})\end{array}$ \\
\hline MRT & $1383.3 \pm 14.3^{\mathrm{d}}$ & - & - \\
\hline MRE & $1004.6 \pm 8.9^{c}$ & - & - \\
\hline Dentatin & - & - & - \\
\hline Nordentatin & - & $41.9 \pm 0.8^{a}$ & - \\
\hline Clausine K & - & $21.9 \pm 0.8^{b}$ & $179.5 \pm 1.7^{\mathrm{a}}$ \\
\hline $\operatorname{Re} 1$ & - & - & - \\
\hline $\operatorname{Re} 2$ & $573.8 \pm 14.3^{b}$ & - & ne \\
\hline $\operatorname{Re} 3$ & - & - & $1798.0 \pm 20.3^{c}$ \\
\hline Re4 & - & - & $243.8 \pm 2.7^{a}$ \\
\hline $\operatorname{Re} 5$ & - & - & $2897.3 \pm 25.0^{\mathrm{d}}$ \\
\hline \multicolumn{4}{|l|}{ Control } \\
\hline Acarbose & $39.6 \pm 1.4^{\mathrm{a}}$ & $n d$ & nd \\
\hline Oleanolic acid $\left(\mathrm{IC}_{50}\right)$ & nd & $0.3 \pm 0.0$ & nd \\
\hline Myricetin & nd & nd & $735.6 \pm 7.2^{b}$ \\
\hline
\end{tabular}

Basically, the biological activity of a mixture is not only defined by the content of compounds but also relies upon the compound type or its chemical structure, in which, the functional group plays a crucial role. While the antioxidant activity is merely characterized by the number of hydrogen donors, the enzymatic inhibitory activity is more complicated and is defined by various factors of the chemical structure aspect [38]. For instance, an anti- $\alpha$-amylase flavonoid requires to possess hydrogen bonds between the hydroxyl groups of the polyphenol ligands and the catalytic residues of the binding site [39]. In the case of mimosine, a known tyrosinase inhibitor from Mimosoideae family, its structure contains an active pyridine ring linked with the ketohydroxy and amino carboxylic groups which may exert its potent biological activities [40]. To be more specific, the position of functional groups along with bonding types are considered as the prerequisite determinants for the bioactivity of a compound. In the present study, the replacement of the hydroxy group by the methoxy one at C-5 of the seselin skeleton resulted in an inactive antioxidant and elastase inhibitor, such as dentatin. Furthermore, the results suggested that the carbazole-like structure is more inhibitory of tyrosinase reaction rather than the seselin coumarin structure. However, dentatin, nordentatin and clausine $\mathrm{K}$ were manifested to be antibacterial [41], antifungal [42], antiplasmodial [19], anti-HIV-1 [43,44], and anti-hepatitis B virus (HBV) [45] agents. Moreover, these compounds were substantiated with persuasive anticarcinogenic properties in various cancer cells including colon, lung, oral human epidermal carcinoma, kidney, cholangiocarcinoma and others [7,15,16,32,46]. Hence, the quantification of these precious phytochemicals is genuinely essential for researching and developing natural drugs.

\subsection{Dentatin, Nordentatin and Clausine K Contents in Clausena indica Roots' Extract}

The contents of dentatin, nordentatin and clausine $\mathrm{K}$ were successfully quantified by using high-performance liquid chromatography (HPLC). The HPLC chromatogram of MRT and MRE extracts and purified compounds from C. indica root is sketched in Figure 2. A good separation of phytochemicals under $270 \mathrm{~nm}$ was observed, in which, dentatin, nordentatin and clausine $\mathrm{K}$ were detected at the retention times of 16.5, 15.4, and $11.9 \mathrm{~min}$, respectively. The similar components obtained from HPLC for MRT (Figure 2d) and MRE (Figure 2e) extracts suggested the ethyl acetate separation could gain most of the major compounds from the $C$. indica root. Basing on the linear equation established from the calibration curve, the quantities of dentatin, nordentatin, and clausine 
$\mathrm{K}$ in the MRT extract were correspondingly measured as $14.74,6.14$, and $1.28 \mathrm{mg} / \mathrm{g}$ dry weight of C. indica roots.
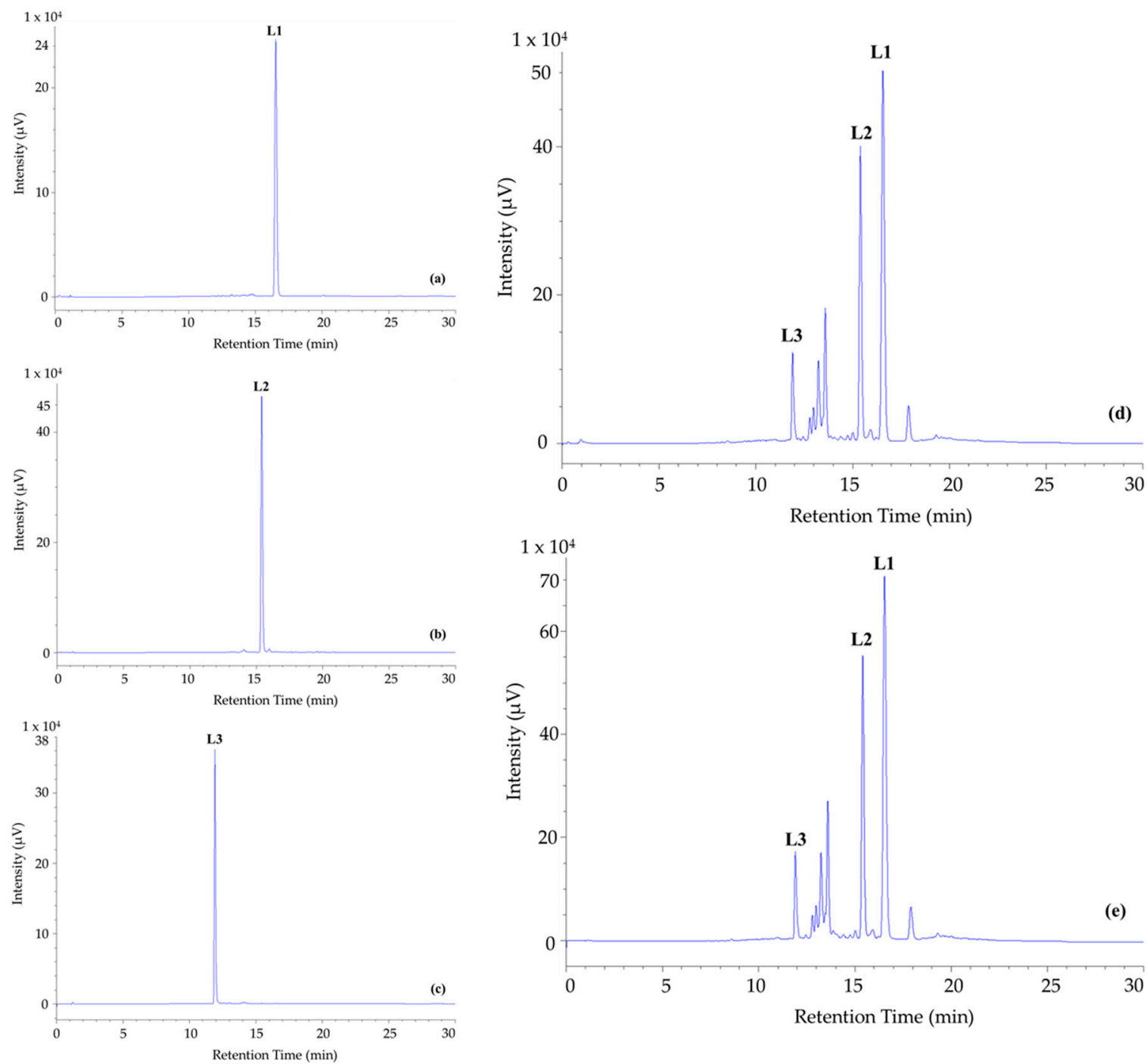

Figure 2. High-performance liquid chromatography (HPLC) chromatographic profile at $270 \mathrm{~nm}$ of isolated compounds from Clausena indica roots. (a) dentatin-L1; (b) nordentatin-L2; (c) clausine K-L3; (d) methanolic extract (MRT); (e) ethyl acetate extract (MRE).

In fact, the quantification of the bioactive substances dentatin, nordentatin, and clausine $\mathrm{K}$ by HPLC-UV were described by Wangboonskul and colleagues [47]. In the present study, we developed a new system by simplifying the gradient component coupled with a reversed-phase HPLC column that helped to increase the sensitivity and shorten the operation time. In particular, in this study, the limits of detection (LOD) and the limits of quantitation (LOQ) values for dentatin, nordentatin, and clausine K were more sensitive than those of Wangboonskul's method by 625 and 514, 392 and 316, 188 and 253 times, respectively.

The quantified amounts of dentatin, nordentatin, and clausine $\mathrm{K}$ by HPLC were in line with those of the isolated compounds by column chromatography (dentatin > nordentatin > clausine $\mathrm{K}$ ). The HPLC results suggested that other active components in C. indica roots could be prospectively detected by using advanced techniques, such as liquid chromatography equipped with tandem mass spectrometry (LC-MS-MS). The use of a reversed-phase column and gradient system described in this study can be employed and incorporated with more sensitive detectors and separators in order to purify and elucidate more bioactive components in C. indica roots. 


\section{Materials and Methods}

\subsection{General Experimental Procedures}

The X-ray intensity data were measured on a Bruker D8 goniometer system equipped with a Bruker Turbo X-ray Source rotating-anode X-ray tube (MoKa, $\lambda=0.71073 \AA$ ) and a multilayered confocal mirror monochromator. ${ }^{1} \mathrm{H}$ - and ${ }^{13} \mathrm{C}$-NMR spectra were acquired on a Bruker Ascend $400 \mathrm{MHz}$ NMR spectrometer (BRUKER BioSpin, Faellanden, Switzerland) at 400 and $125 \mathrm{MHz}$, respectively. LTQ Orbitrap XL mass spectrometer (Thermo Fisher Scientific, Waltham, MA, USA) equipped with a source of electrospray ionization (ESI) was employed to get ESI-MS spectra of pure compounds. A Jasco HPLC system consisting of PU-4180 RHPLC pump, LC-Net II/ADC controller, and UV-4075 UV/Vis detector (Jasco, Tokyo, Japan) and the GC-MS system (JMS-T100 GCV, JEOL Ltd., Tokyo, Japan) were used to identify bioactive constituents. Biological activities were in vitro assayed by using a Multiskan ${ }^{\mathrm{TM}}$ microplate spectrophotometer (Thermo Fisher Scientific, Osaka, Japan) and U-shape microplates (Greiner Bio-one, Monroe, NC, USA). Reagents, solvents, and chemicals at high grades were purchased from Fujifilm Wako Pure Chemical Corporation (Osaka, Japan), Junsei Chemical Co., Ltd. (Tokyo, Japan), Fisher Scientific company (Hampton, NH, USA) and Sigma-Aldrich (St. Louis, MO, USA).

\subsection{Materials}

Roots of Clausena indica were collected in Bac Kan province, Vietnam in March 2019. The identification of the species was morphologically done basing on Plants Database Missouri Botanical Garden, United States (TROPICOS—http://www.tropicos.org) and Vietnam Plant Data Center (http://www.botanyvn.com). The voucher specimen number MMR-J2019 was preserved at the Laboratory of Plant Physiology and Biochemistry, IDEC, Hiroshima University, Japan.

\subsection{Sample Preparation, Extraction and Isolation}

The collected $C$. indica roots were washed by tap water then immersed in $0.5 \%$ sodium hypochlorite $(\mathrm{NaClO})$ for $30 \mathrm{~min}$ to remove soil, bacteria and other impurities. Afterward, the sample was washed several times with distilled water and dried at $40{ }^{\circ} \mathrm{C}$ by a convection oven for 10 days. The dried roots were shredded and ground to make powder. Subsequently, the root powder (140 g) was extracted 3 times by $500 \mathrm{~mL}$ of methanol (MeOH, 99.8\%) for 5 days. After combination, $\mathrm{MeOH}$ was evaporated by the Rotavapor ${ }^{\circledR}$ R-300 (Nihon Buchi K.K., Tokyo, Japan) and the total crude extract (MRT, 11 g) was obtained. The MRT was homogenized in $100 \mathrm{~mL}$ distilled water, then fractionated by hexane and ethyl acetate to yield hexane (MRH, $82 \mathrm{mg}$ ) and ethyl acetate (MRE, $7.2 \mathrm{~g}$ ), respectively. A screening on biological activities of all extracts and fractions was preliminarily implemented. The strong active extracts were selected for further analysis. The negligible or none active ones (aqueous residue) were discarded.

The MRE extract was subjected to column chromatography over silica gel (200-400 mesh, $40 \mathrm{~g})$, using chloroform/methanol as mobile phase (100:0 to 98:2, v/v) to yield 5 fractions (Re1-Re5). Out of the separated fractions, Re1-Re4 fractions were collected from the 100\% chloroform elution, meanwhile, Re5 was obtained from the chloroform/ $\mathrm{MeOH}(98: 2, v / v)$ elution. After drying at room temperature, three compounds were purified including L1 (750 mg) from Re1, L2 (550 mg) from Re3, and L3 (80 mg) from Re5. Similarities among fractions and purities of isolated compounds were tested by thin-layer chromatography (TLC) and HPLC. Extracts, fractions and pure compounds were dissolved in $\mathrm{MeOH}$ and dimethyl sulfoxide (DMSO) for further biological assays. The extraction and isolation processes are delineated in Figure 3. 


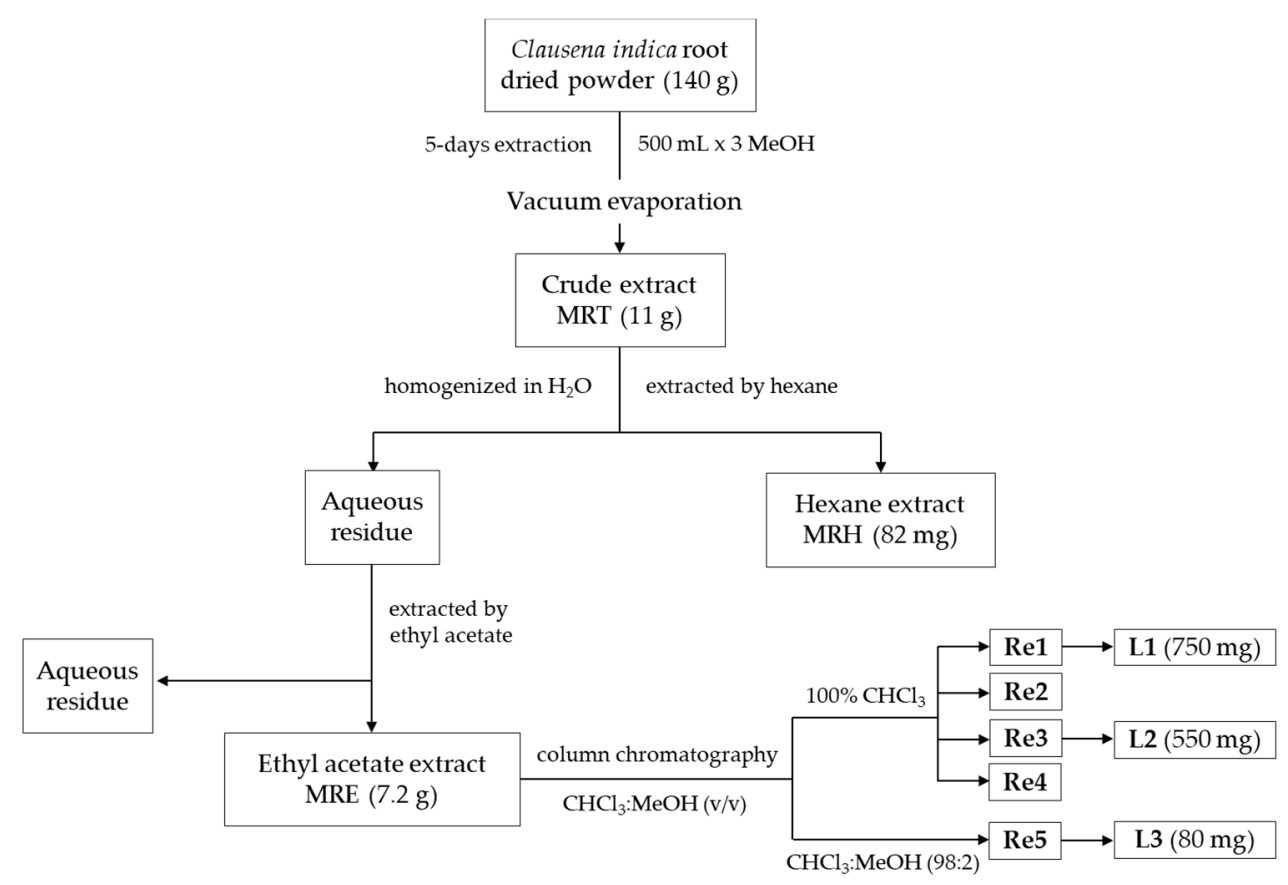

Figure 3. Isolation procedure of bioactive constituents from Clausena indica root extract.

\subsection{Biological Assays}

Samples were prepared in either methanol or DMSO with a range of concentrations $0.01-10 \mathrm{mg} / \mathrm{mL}$ in bio-assays. Each assay was conducted in triplicate and repeated three times. The dose-response curve for each sample was obtained and used to establish the corresponding linear curve for $\mathrm{IC}_{50}$ value calculation, see supplementary data, Figures S5 and S6.

\subsubsection{Antioxidant Activities}

The antioxidant capacity of bioactive constituents from $C$. indica roots was examined by DPPH radical scavenging, ABTS radical cation discoloration and $\beta$-carotene bleaching assays following methods described previously [37] with minor modifications.

In DPPH assay, the mixture of the methanolic sample $(80 \mu \mathrm{L}), 0.5 \mathrm{mM} \mathrm{DPPH}(40 \mu \mathrm{L})$ and $80 \mu \mathrm{L}$ of acetate buffer ( $0.1 \mathrm{M}, \mathrm{pH} 5.5)$ was incubated for $15 \mathrm{~min}$ at $25^{\circ} \mathrm{C}$ [33]. The absorbance was recorded at $517 \mathrm{~nm}$ by the microplate reader. Whereas, the working solution of ABTS radical cation was prepared by the same procedure [37] prior to checking with C. indica samples. Briefly, $2.45 \mathrm{mM}$ potassium persulfate was mixed with aqueous ABTS $(7 \mathrm{mM})$ solution $(1: 1, v / v)$ and incubated in darkness at room temperature for $16 \mathrm{~h}$. The working solution was then obtained by diluting ABTS cation solution in methanol. In a well of the microplate, $20 \mu \mathrm{L}$ of methanolic sample was mixed with $180 \mu \mathrm{L}$ of the above working solution. The mixture was then incubated for $20 \mathrm{~min}$ at $25^{\circ} \mathrm{C}$ and the absorbance was read at $734 \mathrm{~nm}$. Both DPPH and ABTS assays were conducted under the avoidance of light. Butylated hydroxytoluene (BHT) was used as positive control while $\mathrm{MeOH}$ was negative one. The radical scavenging percentage was calculated as follows:

$$
\text { Radical scavenging activity }(\%)=\left[1-\left(\mathrm{S}-\mathrm{B}_{\mathrm{S}}\right)\right] /\left(\mathrm{C}-\mathrm{B}_{\mathrm{C}}\right) \times 100
$$

where $\mathrm{C}$ is the absorbance of the reaction with negative control (methanol), $\mathrm{S}$ is the absorbance of reaction with sample or positive control (BHT), $\mathrm{B}_{\mathrm{C}}$ (blank of control) is the absorbance of negative control sample without radical solution, $\mathrm{B}_{\mathrm{S}}$ (blank of sample) is the absorbance of tested sample without radical solution. The $\mathrm{IC}_{50}$ value was determined as the concentration needed to reduce $50 \%$ of the radical absorbance by a linear equation acquired from the dose-response curve (Figures S5 and S6). 
In $\beta$-carotene bleaching test, $25 \mu \mathrm{L}$ of methanolic samples $(500 \mu \mathrm{g} / \mathrm{mL})$ was blended with $200 \mu \mathrm{L}$ of an emulsion containing $\beta$-carotene $(4 \mu \mathrm{g} / \mathrm{mL})$ and linoleic acid $(0.04 \%)$. The reaction was implemented at $45{ }^{\circ} \mathrm{C}$ and the reduction of $\beta$-carotene was recorded at $492 \mathrm{~nm}$ every $15 \mathrm{~min}$ up to $180 \mathrm{~min}$. The antioxidant activity was expressed by the lipid peroxidation inhibition (LPI in \%) which was calculated as the earlier formula [37].

\subsection{2. $\alpha$-Amylase Inhibitory Assay}

Porcine pancreatic $\alpha$-amylase (PPA) inhibition of $C$. indica extracts and isolated compounds was determined by the starch-iodine method [48]. In summary, a tested sample $(20 \mu \mathrm{L})$ was incubated with an equal volume of PPA $(20 \mathrm{U} / \mathrm{mL})$ at $37^{\circ} \mathrm{C}$ for $10 \mathrm{~min}$. The reaction was initiated by adding $30 \mu \mathrm{L}$ of starch solution ( $0.5 \%$ ). The reaction was performed in $8 \mathrm{~min}$ at $37^{\circ} \mathrm{C}$ before being stopped by $1 \mathrm{M} \mathrm{HCl}$ and then fixing by $100 \mu \mathrm{L}$ of $0.25 \mathrm{mM}$ iodine. The suppression of starch digestion by tested samples was measure at $565 \mathrm{~nm}$. The inhibitory activity was delineated by the $\mathrm{IC}_{50}$ value. Acarbose was used as a reference.

$$
\text { Inhibition percentage }(\%)=(A-C) /(B-C) \times 100
$$

where $\mathrm{A}$ is the absorbance of reaction with the presence of sample or acarbose, $\mathrm{B}$ is the absorbance of reaction without enzyme, $\mathrm{C}$ is the absorbance of reaction with the absence of sample or acarbose.

\subsubsection{Elastase and Tyrosinase Inhibitory Assay}

The inhibitory effects of $C$. indica extracts and isolated compounds on the key enzymes related to skin problems elastase and tyrosinase were assessed by the protocol reported by Chompoo et al. [35] with several adjustments.

In particular, $20 \mu \mathrm{L}$ of a sample (in DMSO) was added to $180 \mu \mathrm{L}$ of the substrate buffer $(1 \mathrm{mM}$ SANA in $0.1 \mathrm{M}$ Tris-HCl buffer, $\mathrm{pH} 8.0$ ). The solution was mixed and maintained for $5 \mathrm{~min}$ at $25^{\circ} \mathrm{C}$. The reaction was started by adding $20 \mu \mathrm{L}$ of pancreatic elastase $(0.1 \mathrm{U} / \mathrm{mL})$. After 12 min of incubation at $25^{\circ} \mathrm{C}$, the absorbance was measured at $410 \mathrm{~nm}$. Oleanolic acid and DMSO were used as positive and negative controls, respectively.

Twenty microliters of sample were mixed with $120 \mu \mathrm{L}$ of phosphate buffer $(20 \mathrm{mM}, \mathrm{pH} 6.8)$ and $20 \mu \mathrm{L}$ of tyrosinase $\left(500 \mathrm{U} / \mathrm{mL}\right.$ in buffer), respectively. After a five minutes-incubation at $25^{\circ} \mathrm{C}, 50 \mu \mathrm{L}$ of $2 \mathrm{mM}$ L-tyrosine substrate was pipetted to start the reaction. The mixture was slightly shaken and incubated for another $10 \mathrm{~min}$ at $25^{\circ} \mathrm{C}$ prior to being measured under $470 \mathrm{~nm}$. Myricetin and vanillin were used as positive references whereas DMSO was the negative control. The inhibition percentage of enzymatic assays was computed as:

$$
\text { Inhibition }(\%)=[1-(C-D) /(A-B)] \times 100
$$

where $\mathrm{A}$ is the absorbance of the control with the enzyme, $\mathrm{B}$ is the absorbance of the control without the enzyme, $C$ is the absorbance of the sample with the enzyme, and $D$ is the absorbance of the sample without the enzyme. The $\mathrm{IC}_{50}$ value was defined as the concentration of a sample that suppressed $50 \%$ of the enzymatic reaction over the negative control (Figures S5 and S6).

\subsection{Identification and Confirmation of Isolated Compounds and other Phytochemical Constituents}

The structures and chemical formula of isolated compounds L1, L2 and L3 were identified and confirmed by X-ray diffraction, ${ }^{1} \mathrm{H}$ - and ${ }^{13} \mathrm{C}$-NMR and the flow injection analysis (FIA) coupled with electrospray ionization tandem mass spectrometric (FIA-ESI-MS-MS). By X-ray experiment, the crystal sample was exposed to X-ray for 0.80 hours at $-100^{\circ} \mathrm{C}$. The frames were integrated with the Bruker SAINT software package using a narrow-frame algorithm. Data were corrected for absorption effects using the Multi-Scan method (SADABS). The structure was solved and refined using the Bruker SHELXTL software package. Meanwhile, ${ }^{1} \mathrm{H}$ - and ${ }^{13} \mathrm{C}-\mathrm{NMR}$ spectra were analyzed and elucidated by Bruker Topspin software version 3.2. Additionally, MS-MS spectra of isolated compounds were 
acquired by FIA-ESI-MS-MS using a positive model. In summary, isolated compounds were dissolved in $\mathrm{MeOH}$ :acetonitrile $(1: 1, v / v)$ to make a concentration of $100 \mu \mathrm{g} / \mathrm{mL}$. One microliter of each sample was automatically injected to the ESI system which was set up as follows: ion source voltage $(4.5 \mathrm{kV})$, capillary voltage $(50 \mathrm{~V})$, tube lens offset $(80 \mathrm{~V})$, capillary temperature $\left(330^{\circ} \mathrm{C}\right)$, vaporizer temperature $\left(-65^{\circ} \mathrm{C}\right)$. The gas carrier was nitrogen with the sheath flow rate of $50 \mathrm{arb}$, and the aux flow rate of 10 arb [49]. The full-scan and data-independent scan spectra for MS-MS on [M + H] $]^{+}$were achieved and processed by using Xcalibur software integrated with the NIST database. The online database (Pubchem, National Center for Biotechnology Information, U.S. National Library of Medicine, Bethesda, MD, USA) and the literature were used for references.

Dentatin (L1): pale yellow plate $\left(\mathrm{CHCl}_{3}\right)$, ESI-MS m/z $327.1593[\mathrm{M}+\mathrm{H}]^{+}$(calcd for $\left.\mathrm{C}_{20} \mathrm{H}_{23} \mathrm{O}_{4}, 327.1596\right)$, Figure S1, crystal data see Table $1 .{ }^{1} \mathrm{H}-\mathrm{NMR}$ and ${ }^{13} \mathrm{C}-\mathrm{NMR}$ signals were closely coincident with those reported in literatures (Table S1) [16,25,32,41].

Nordentatin (L2): light yellow block (MeOH), ESI-MS m/z $313.1434[\mathrm{M}+\mathrm{H}]^{+}$(calcd for $\mathrm{C}_{19} \mathrm{H}_{21} \mathrm{O}_{4}$, 313.1440), Figure S2, crystal data see Table $1 .{ }^{1} \mathrm{H}-\mathrm{NMR}$ and ${ }^{13} \mathrm{C}-\mathrm{NMR}$ data were in good agreement with those in the literature (Table S2) [16,25,32].

Clausine K (L3): clear yellow block (DMSO), ESI-MS m/z $272.0914[\mathrm{M}+\mathrm{H}]^{+}$(calcd for $\mathrm{C}_{15} \mathrm{H}_{14} \mathrm{O}_{4} \mathrm{~N}_{\text {, }}$ 272.0923), Figure S3, crystal data see Table $1 .{ }^{1} \mathrm{H}-\mathrm{NMR}$ and ${ }^{13} \mathrm{C}-\mathrm{NMR}$ spectra were in line with published data (Table S3) $[16,19,25]$.

Other phytochemical constituents from C. indica root extract and fractions were identified by gas chromatography-mass spectrometry (GC-MS). The system equipped with a $30 \mathrm{~m} \times 0.25 \mathrm{~mm}$ I.D. $\times$ $0.25 \mu \mathrm{m}$ film thickness DB-5MS column (Agilent Technologies, J \& W Scientific Products, Folsom, CA, USA). The operating condition was imposed following the previous method [37]. In brief, $1 \mu \mathrm{L}$ of the sample was injected into the GC system by an auto-sampler. The temperatures of injection port and detector temperature were set at $300{ }^{\circ} \mathrm{C}$ and $320^{\circ} \mathrm{C}$, respectively. The carrier gas was helium at inlet control with a split ratio of 5:1. The initial temperature of GC oven was $50{ }^{\circ} \mathrm{C}$, after a boosting up to $300{ }^{\circ} \mathrm{C}$ with a rate of $10{ }^{\circ} \mathrm{C} / \mathrm{min}$, the oven temperature was maintained for $20 \mathrm{~min}$. The mass range was recorded from 29 to 800 amu. The software JEOL's GC-MS Mass Center System version 2.65a was occupied to analyze mass spectra of the natural components.

\subsection{Quantification of Dentatin, Nordentatin and Clausine K contents by HPLC-UV/VIS}

The contents of isolated compounds in C. indica root were quantified by the HPLC with a UV/Vis

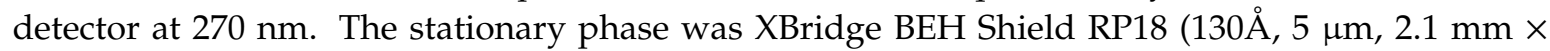
$100 \mathrm{~mm}$ ) column (Waters Cooperation, Milford, MA, USA). The mobile phase consisted of solution A $(0.1 \%$ aqueous formic acid) and solution B (100\% acetonitrile), which was adjusted in a gradient program as follows: 5\% B during 0-2 min, a linear increase from 5 to $70 \% \mathrm{~B}$ during $2-12 \mathrm{~min}, 100 \%$ B from 12-16 min and maintained for $6 \mathrm{~min}, 100 \%$ B to 5\% during 22-24 min and other $10 \mathrm{~min}$ for equilibration. The injection volume was $3 \mu \mathrm{L}$ and the flow rate was $400 \mu \mathrm{L} / \mathrm{min}$. The operation was carried out in $35 \mathrm{~min}$ under room temperature. The corresponding peaks from a sample were detected and their areas were used to calculate the amount (mg per $\mathrm{g}$ dry weight, $\mathrm{mg} / \mathrm{g} \mathrm{DW}$ ) over the standard curve built from the isolated dentatin, nordentatin, and clausine K. The linearity of system was observed in the range of $5-100 \mu \mathrm{g} / \mathrm{mL}$ with correlation coefficients $\left(\mathrm{r}^{2}\right)$ of 0.9992 for dentatin, 0.9991 for nordentatin, and 0.9996 for clausine K. The limits of detection (LOD) were $0.12,0.13$, and $0.09 \mathrm{ng} / \mathrm{mL}$ for dentatin, nordentatin, and clausine $\mathrm{K}$, respectively, meanwhile, the limits of quantitation (LOQ) for these compounds were $0.36,0.38$, and $0.26 \mathrm{ng} / \mathrm{mL}$.

\subsection{Statistical Analyses}

Results were displayed as mean \pm standard error (SE). The statistically significant differences among samples were determined by ANOVA followed by Tukey's multiple comparison test $(p<0.05)$. 
All observations were conducted three times $(n=3)$, and the data were analyzed by Minitab software version 16.0 (Minitab Inc., State College, PA, USA). The $\mathrm{IC}_{50}$ value was calculated by plotting the graph (Microsoft Excel, version 1902, Microsoft, Redmond, WA, USA) between the different concentrations of a tested sample and the corresponding percent inhibitions.

\section{Conclusions}

The bio-guided isolation of the ethyl acetate extract from Clausena indica roots achieved three known compounds dentatin, nordentatin, and clausine $\mathrm{K}$. The compounds have been previously reported in C. excavata, but their presence in C. indica are described for the first time herein. Except for dentatin and fraction Re1, all fractions, nordentatin and clausine K exerted promising antioxidant activities. The fraction $\mathbf{R e} 2$ is responsible for the anti- $\alpha$-amylase effect while clausine $K$ and the fraction Re4 are pioneering tyrosinase inhibitors of $C$. indica roots. Bioactive constituents of the plant extracts and fractions were provisionally characterized by GC-MS, the most abundant analytes might belong to carbazole alkaloids. The modern techniques and further isolations should be implemented in exploiting and discovering prospective active compounds from this plant.

Supplementary Materials: The following are available online, Figures S1-S3: Total ion chromatography (upper) and tandem mass spectrometry (MS-MS) spectrum (lower) of dentatin, nordentatin, clausine K; Figure S4: GC-MS fragmentation patterns of UC1 (a), UC2 (b), and UC3 (c) detected in Clausena indica roots; Figure S5: Dose-response curves for biological activities of major active constituents isolated from Clausena indica roots and positive controls; Figure S6: Linear curves used to calculate $\mathrm{IC}_{50}$ of biological activities of major active constituents isolated from Clausena indica roots; Table S1, S2, S3: ${ }^{1} \mathrm{H}(400 \mathrm{MHz})$ and ${ }^{13} \mathrm{C}(101 \mathrm{MHz}) \mathrm{NMR}$ spectral data of dentatin, nordentatin, clausine $\mathrm{K}$.

Author Contributions: N.V.Q. and T.D.X. designed and carried out all experiments; L.H.A. determined antioxidant activities; H.-D.T. assembled and revised the manuscript. All authors contribute to preparing the manuscript.

Funding: This research receives no external funding.

Acknowledgments: The authors thank Le Thu Trang for her supports to sample preparation and isolation steps. Professor Abe Manabu, Pham Thi Thu Thuy, and Nguyen Ngoc Thanh Luan are appreciated for assistance in operating and analyzing NMR spectra.

Conflicts of Interest: The authors declare no conflict of interest.

\section{References}

1. Diep, P.T.M.; Pawlowska, A.M.; Cioni, P.L.; Van Minh, C.; Huong, L.M.; Braca, A. Chemical composition and antimicrobial activity of Clausena indica (Dalz) Oliv. (Rutaceae) essential oil from Vietnam. Nat. Prod. Commun. 2009, 4, 869-872. [CrossRef] [PubMed]

2. John, J.A.; Kurup, S.R.R.; Pradeep, N.S.; Sabulal, B. Chemical composition and antibacterial activity of the leaf oil of Clausena indica from South India. J. Essent. Oil Bear. Plants 2011, 14, 776-781. [CrossRef]

3. Joshi, B.S.; Gawad, D.H. Isolation of some furanocoumarins from Clausena indica and identity of chalepensin with xylotenin. Phytochemistry 1971, 10, 480-481. [CrossRef]

4. Joshi, B.S.; Gawad, D.H.; Kamat, V.N. 6-Methoxyheptaphylline, a new carbazole alkaloid from Clausena indica Oliv. Indian J. Chem. 1972, 10, 1123-1124.

5. Joshi, B.S.; Kamat, V.N.; Gawad, D.H. Clausindine, a novel cyclopropylcoumarin. J. Chem. Soc. Perkin Trans. 1 1974, 1561-1564. [CrossRef]

6. Joshi, B.S.; Gawad, D.H.; Williams, D.J. The structure of clausantalene, a new sesquiterpene from Clausena indica Oliv. Experientia 1975, 31, 138-139. [CrossRef]

7. Huang, L.; Feng, Z.-L.; Wang, Y.-T.; Lin, L.-G. Anticancer carbazole alkaloids and coumarins from Clausena plants: A review. Chin. J. Nat. Med. 2017, 15, 881-888. [CrossRef]

8. Aruoma, O.I. Free radicals, oxidative stress, and antioxidants in human health and disease. J. Am. Oil Chem. Soc. 1998, 75, 199-212. [CrossRef]

9. Czarnocka, W.; Karpiński, S. Friend or foe? Reactive oxygen species production, scavenging and signaling in plant response to environmental stresses. Free Radic. Biol. Med. 2018, 122, 4-20. [CrossRef] 
10. Koepke, J.I.; Wood, C.S.; Terlecky, L.J.; Walton, P.A.; Terlecky, S.R. Progeric effects of catalase inactivation in human cells. Toxicol. Appl. Pharmacol. 2008, 232, 99-108. [CrossRef]

11. Linda, G.H. Dermatological complications of obesity. Am. J. Clin. Dermatol. 2002, 3, 497-506.

12. Demirseren, D.D.; Emre, S.; Akoglu, G.; Arpac1, D.; Arman, A.; Metin, A.; Cakır, B. Relationship between skin diseases and extracutaneous complications of diabetes mellitus: Clinical analysis of 750 patients. Am. J. Clin. Dermatol. 2014, 15, 65-70. [CrossRef] [PubMed]

13. Jain, S.; Dwivedi, J.; Jain, P.K.; Satpathy, S.; Patra, A. Medicinal plants for treatment of cancer: A brief review. Pharmacogn. J. 2016, 8, 87-102. [CrossRef]

14. Umeno, A.; Horie, M.; Murotomi, K.; Nakajima, Y.; Yoshida, Y. Antioxidative and antidiabetic effects of natural polyphenols and isoflavones. Molecules 2016, 21, 708. [CrossRef]

15. Songsiang, U.; Thongthoom, T.; Boonyarat, C.; Yenjai, C. Claurailas A-D, cytotoxic carbazole alkaloids from the roots of Clausena harmandiana. J. Nat. Prod. 2011, 74, 208-212. [CrossRef]

16. Songsiang, U.; Thongthoom, T.; Zeekpudsa, P.; Kukongviriyapan, V.; Boonyarat, C.; Wangboonskul, J.; Yenjai, C. Antioxidant activity and cytotoxicity against cholangiocarcinoma of carbazoles and coumarins from Clausena harmandiana. ScienceAsia 2012, 38, 75. [CrossRef]

17. Carrillo, W.; Greffa, J.; Vinueza, D.; Álvarez, M.; Silva, M.; Carpio, C.; Morales, D. Fatty acids content of kahai (Caryodendron orinocense Karst) seeds cultivated in Amazonian of Ecuador. Asian J. Pharm. Clin. Res. 2018, 11, 399-402.

18. Mukandiwa, L.; Ahmed, A.; Eloff, J.N.; Naidoo, V. Isolation of seselin from Clausena anisata (Rutaceae) leaves and its effects on the feeding and development of Lucilia cuprina larvae may explain its use in ethnoveterinary medicine. J. Ethnopharmacol. 2013, 150, 886-891. [CrossRef]

19. Yenjai, C.; Sripontan, S.; Sriprajun, P.; Kittakoop, P.; Jintasirikul, A.; Tanticharoen, M.; Thebtaranonth, Y. Coumarins and carbazoles with antiplasmodial activity from Clausena harmandiana. Planta Med. 2000, 66, 277-279. [CrossRef]

20. National Center for Biotechnology Information. PubChem Database. Braylin, CID =618370. Available online: https://pubchem.ncbi.nlm.nih.gov/compound/Braylin (accessed on 26 September 2019).

21. Kumatia, E.K.; Annan, K.; Dickson, R.A.; Mensah, A.Y.; Amponsah, I.K.; Appiah, A.A.; Tung, N.H.; Edoh, D.A.; Habtemariam, S. Anti-inflammatory and analgesic effects in rodent models of ethanol extract of Clausena anisata roots and their chemical constituents. Nat. Prod. Commun. 2017, 12, 67-72. [CrossRef]

22. National Center for Biotechnology Information. PubChem Database. Clionasterol, CID = 457801. Available online: https://pubchem.ncbi.nlm.nih.gov/compound/Clionasterol (accessed on 26 September 2019).

23. Thongthoom, T.; Songsiang, U.; Phaosiri, C.; Yenjai, C. Biological activity of chemical constituents from Clausena harmandiana. Arch. Pharm. Res. 2010, 33, 675-680. [CrossRef] [PubMed]

24. Shi, X.-J.; Ye, G.; Tang, W.-J.; Zhao, W.-M. A new coumarin and carbazole alkaloid from Clausena vestita D. D. $\mathrm{T}_{\mathrm{AO}}$. Helvetica Chimica Acta 2010, 93, 985-990. [CrossRef]

25. Wu, T.-S.; Huang, S.-C.; Wu, P.-L.; Teng, C.-M. Carbazole alkaloids from Clausena excavata and their biological activity. Phytochemistry 1996, 43, 133-140. [PubMed]

26. Taufiq-Yap, Y.H.; Peh, T.H.; Ee, G.C.L.; Rahmani, M.; Sukari, M.A.; Ali, A.M.; Muse, R. A new cytotoxic carbazole alkaloid from Clausena excavata. Nat. Prod. Res. 2007, 21, 810-813. [CrossRef]

27. Fun, H.-K.; Maneerat, W.; Laphookhieo, S.; Chantrapromma, S. 2-Hydroxy-7-methoxy-9H-carbazole-3-carbaldehyde. Acta Crystallogr. Sect. E Struct. Rep. Online. 2010, 66, o2418-o2419. [CrossRef]

28. Wu, T.-S.; Huang, S.-C. Clausine-D and -F, two new 4-prenylcarbazole alkaloids from Clausena excavata. Chem. Pharm. Bull. 1992, 40, 1069-1071. [CrossRef]

29. Rakash, D.; Raj, K.; Kapil, R.S.; Popli, S.P. Coumarins from Clausena indica. Phytochemistry 1978, 17, $1194-1195$. [CrossRef]

30. Riemer, B.; Hofer, O.; Greger, H. Tryptamine derived amides from Clausena indica. Phytochemistry 1997, 45, 337-341. [CrossRef]

31. Trung, H.D.; Thang, T.D.; Ban, P.H.; Hoi, T.M.; Dai, D.N.; Ogunwande, I.A. Terpene constituents of the leaves of five Vietnamese species of Clausena (Rutaceae). Nat. Prod. Res. 2014, 28, 622-630. [CrossRef]

32. Jantamat, P.; Weerapreeyakul, N.; Puthongking, P. Cytotoxicity and apoptosis induction of coumarins and carbazole alkaloids from Clausena harmandiana. Molecules 2019, 24, 3385. [CrossRef] 
33. Pękal, A.; Pyrzynska, K. Effect of $\mathrm{pH}$ and metal ions on DPPH radical scavenging activity of tea. Int. J. Food Sci. Nutr. 2015, 66, 58-62. [CrossRef] [PubMed]

34. Su, C.-H.; Lai, M.-N.; $\mathrm{Ng}$, L.-T. Inhibitory effects of medicinal mushrooms on $\alpha$-amylase and $\alpha$-glucosidase-Enzymes related to hyperglycemia. Food Funct. 2013, 4, 644-649. [CrossRef]

35. Balamurugan, R.; Duraipandiyan, V.; Ignacimuthu, S. Antidiabetic activity of $\gamma$-sitosterol isolated from Lippia nodiflora L. in streptozotocin induced diabetic rats. Eur. J. Pharmacol. 2011, 667, 410-418. [CrossRef] [PubMed]

36. Chompoo, J.; Upadhyay, A.; Fukuta, M.; Tawata, S. Effect of Alpinia zerumbet components on antioxidant and skin diseases-related enzymes. BMC Complement. Altern. Med. 2012, 12, 106-114. [CrossRef] [PubMed]

37. Tu, P.T.B.; Tawata, S. Anti-oxidant, anti-aging, and anti-melanogenic properties of the essential oils from two varieties of Alpinia zerumbet. Molecules 2015, 20, 16723-16740. [CrossRef] [PubMed]

38. Quan, N.V.; Xuan, T.D.; Hoang-Dung, T.; Thuy, N.T.D.; Trang, L.T.; Huong, C.T.; Andriana, Y.; Tuyen, P.T. Antioxidant, $\alpha$-amylase and $\alpha$-glucosidase inhibitory activities and potential constituents of Canarium tramdenum bark. Molecules 2019, 24, 605. [CrossRef]

39. Lo Piparo, E.; Scheib, H.; Frei, N.; Williamson, G.; Grigorov, M.; Chou, C.J. Flavonoids for controlling starch digestion: Structural requirements for inhibiting human $\alpha$-amylase. J. Med. Chem. 2008, 51, 3555-3561. [CrossRef]

40. Nguyen, B.C.Q.; Tawata, S. The chemistry and biological activities of mimosine: A review. Phyther. Res. 2016, 30, 1230-1242. [CrossRef]

41. Wu, T.-S.; Furukawa, H. Biological and phytochemical investigation of Clausena excavata. J. Nat. Prod. 1982, 45, 718-720. [CrossRef]

42. Sunthitikawinsakul, A.; Kongkathip, N.; Kongkathip, B.; Phonnakhu, S.; Daly, J.W.; Spande, T.F.; Nimit, Y.; Rochanaruangrai, S. Coumarins and carbazoles from Clausena excavata exhibited antimycobacterial and antifungal activities. Planta Medica 2003, 69, 155-157. [CrossRef]

43. Kongkathip, B.; Kongkathip, N.; Sunthitikawinsakul, A.; Napaswat, C.; Yoosook, C. Anti-HIV-1 constituents from Clausena excavata: Part II. carbazoles and a pyranocoumarin. Phyther. Res. 2005, 19, 728-731. [CrossRef] [PubMed]

44. Sunthitikawinsakul, A.; Kongkathip, N.; Kongkathip, B.; Phonnakhu, S.; Daly, J.W.; Spande, T.F.; Nimit, Y.; Napaswat, C.; Kasisit, J.; Yoosook, C. Anti-HIV-1 limonoid: First isolation from Clausena excavata. Phytother. Res. 2003, 17, 1101-1103. [CrossRef] [PubMed]

45. Su, C.-R.; Yeh, S.F.; Liu, C.M.; Damu, A.G.; Kuo, T.-H.; Chiang, P.-C.; Bastow, K.F.; Lee, K.-H.; Wu, T.-S. Anti-HBV and cytotoxic activities of pyranocoumarin derivatives. Bioorg. Med. Chem. 2009, 17, 6137-6143. [CrossRef] [PubMed]

46. Al-Abboodi, A.; Rasedee, A.; Abdul, A.B.; Taufiq-Yap, Y.H.; Alkaby, W.; Ghaji, M.; Waziri, P.; Al-Qubaisi, M. Anticancer effect of dentatin and dentatin-hydroxypropyl- $\beta$-cyclodextrin complex on human colon cancer (HT-29) cell line. Drug Des. Devel. Ther. 2017, 11, 3309-3319. [CrossRef] [PubMed]

47. Wangboonskul, J.; Tunsirikongkon, A.; Sasithornwetchakun, W. Simultaneous determination of nine analytes in Clausena harmandiana Pierre. by new developed high-performance liquid chromatography method and the influence of locations in Thailand on level of nordentatin and dentatin. Pharmacogn. Mag. 2015, 11, 1-7. [CrossRef]

48. Quan, N.V.; Xuan, T.D.; Hoang-Dung, T.; Ahmad, A.; Khanh, T.D.; Dat, T.D. Contribution of momilactones A and $\mathrm{B}$ to diabetes inhibitory potential of rice bran: Evidence from in vitro assays. Saudi Pharm. J. 2019, 27, 643-649. [CrossRef]

49. Quan, N.V.; Thien, D.D.; Khanh, T.D.; Tran, H.-D.; Xuan, T.D. Momilactones A, B, and tricin in rice grain and by-products are potential skin aging inhibitors. Foods 2019, 8, 602. [CrossRef]

Sample Availability: Samples of the compounds dentatin, nordentatin, and clausine K are available from the authors. 